\title{
Incorporating Demoralization into Social Work Practice
}

\author{
Lynne Briggs and Patricia Fronek
}

\begin{abstract}
This article explores the relevance of demoralization to social work research and practice. Demoralization connects to the very core of being human. It is present in social work client groups and is an important but neglected concept in social work. Demoralization occurs when life becomes so overwhelming that daily functioning is affected and people lose all hope, agency, and the capacity to overcome their circumstances. Although a demoralized state is not recognized as a mental illness in the Diagnostic and Statistical Manual of Mental Disorders, it is often confused with psychiatric disorders and its presence can lead to clinical conditions and suicide. This article discusses demoralization and its place in social work practice, identification, and measurement, and appropriate psychosocial interventions are also explored. The article concludes that demoralization has particular relevance to contemporary social work and should be considered in social work practice and research.
\end{abstract}

KEY WORDS: demoralization; social work practice; vulnerable people

$\mathrm{D}$ emoralization connects to the very core of being human. It is experienced as existential distress and occurs when life becomes so overwhelming that it affects a person's ability to function on a day-to-day basis. Although this concept originated in the early 1960s, it was not accepted in health and psychological disciplines until the last two decades (Clarke \& Kissane, 2002; de Figueiredo, 2013; Frank, 1961; Kissane, 2004; Kissane, Clarke, \& Street, 2001; Sansone \& Sansone, 2010). Recent studies have focused on health care, the elderly, palliative care, and practitioners working in stressful situations (Bobevski, Rowe, Clarke, McKenzie, \& Fisher, 2015; Gabel, 2011, 2012a, 2012b, 2013; Grassi et al., 2017; Kissane, 2014; Kissane et al., 2001; Townsend, 2018; Vehling et al., 2017). Perhaps due to its origins and the complex progression in psychiatric studies of mental illness, demoralization has not as yet become a widely accepted concept in social work practice (Briggs, 2011; Briggs \& Macleod, 2010; Frank, 1961; McKenzie, Clarke, Forbes, \& Sim, 2010). Briggs $(2011,2013)$ is one of the few social workers who has explored the relevance of demoralization to social work practice, particularly in relation to refugee mental health. Her research indicates that the key concepts of demoralization are relevant and useful in social work practice with any group of vulnerable people.
Although social workers consistently work with individuals and groups in which the incidence of demoralization is high, it is often not recognized as such, as it can be confused with other conditions. For example, a recent study of 131 Australian refugees and asylum seekers explored demoralization as a concept distinct from diagnosed mental illness (Hocking \& Sundram, 2015) and found that 79 percent of participants met the criteria for demoralization. External policies, political attitudes, racism, and incarceration combined with past and present experiences of trauma stripped these people of their sense of worth and possibilities for a hopeful future (Briggs, 2011, 2013; Briggs \& Cooper, 2015; Briggs \& Macleod, 2006; Briggs, Talbot, \& Melvin, 2007; Briskman, Zion, \& Loff, 2011).

Demoralization is recognized in terminal or debilitating illness, family breakdowns, and other traumatic or abusive situations (Fang et al., 2014; Kissane et al., 2001). A range of internal and external factors (financial, social, physical, or psychological) and associated interactions all contribute to demoralization, which can affect even the most resilient person. For example, a decline in physical or psychological functioning may result in a withdrawal from social interaction. Kissane (2004) linked demoralization to elderly people who may wish to die. This is unsurprising when they are disabled, dependent, socially isolated, concerned with being a burden, and 
fear a loss of dignity or control. As such, demoralization casts an interesting layer of consideration in current debates about euthanasia, particularly in relation to the elderly tired of living (Florijn, 2018). Butterworth, Fairweather, Anstey, and Windsor (2006) provided insights into the experiences of people demoralized by living on social security benefits. They found that people with little perceived hope of changed future circumstances were demoralized. People experienced hopelessness, as sense of worthlessness, and dissatisfaction with life. Social security beneficiaries comprise the bulk of many social work caseloads. As such, demoralization is a useful concept for social workers in clinical and community practice to understand and intervene with people who are experiencing nonspecific psychological distress.

\section{DEFINING DEMORALIZATION}

Briggs (2013) described demoralization "as a change in morale spanning a spectrum of mental attitudes from disheartenment (mild loss of confidence) through to despondency (starting to give up) and to actually having given up" (p. 27). Demoralization, an enduring state of suffering, is now generally understood to be a normal part of the human condition rather than an abnormal state.

Griffith and Gaby (2005) claimed that demoralization was not a psychiatric condition and should be seen as part of the human experience, and, therefore, does not require pharmacological treatment. There is disagreement in the literature on this point as demoralization can lead to mental health conditions such as clinical depression and suicidality. Kissane (2004) argued that demoralization should be included as a distinct diagnostic category in the Diagnostic and Statistical Manual of Mental Disorders (DSM) because it is different from other conditions. As Cheuk, Chan, and Ungvari (2009) noted, it is the overlap with symptoms of other conditions that makes it so important to recognize demoralization for what it is, as either a diagnostic entity or a separate social or psychosocial phenomenon. Slavney (1999), resisting its medicalization, strongly argued that demoralization, like grief, is a normal reaction to adverse circumstances and is not a psychiatric disorder. According to some theorists, demoralization is multidimensional, occuring when the impact on daily life becomes debilitating, gradually building in intensity and becoming a perpetual state through a series of defined stages (Nanni, Caruso, Sabato, \& Grassi, 2018; Tecuta, Tomba, Grandi, \& Fava, 2015).

\section{Demoralization or Depression}

Although demoralization should not be confused with clinical depression, it can progress to a depressive state and suicidality (Kissane et al., 2001). Thus, it is important for social workers to identify its presence. The main distinction between demoralization and depression is determined by the presence of anhedonia (an inability to feel pleasure), which is also present in grief. People who are depressed experience anhedonia whereas people who are demoralized experience subjective incompetence. Subjective incompetence and personal distress are the main features of demoralization (de Figueiredo \& Frank, 1982). Subjective incompetence describes a person perceiving difficulty expressing emotions (as opposed to not feeling them) due to impaired daily functioning (de Figueiredo \& Frank, 1982). People with depression know the direction of an action they want to take but lack the motivation to achieve it, whereas people who are demoralized may be motivated, but their sense of incompetency and uncertainty (or lack of direction) prohibit action. People who are demoralized can also feel happiness in the moment (consummatory pleasure) but cannot perceive anticipatory pleasure or possibilities of future happiness. Depression, distress, anxiety, grief, and adjustment (which have lower severity) can also coexist with demoralization.

There is potential for mental health professionals to mistake demoralization for depression, anxiety, or adjustment disorders, which, in turn, can lead to ineffective interventions that cause further harm. Demoralization also differs from an adjustment reaction, a symptom-oriented diagnosis of reacting to a past or present problematic environment. The nature and chronicity of environmental and internal factors; lack of agency; and persistent experience of hopelessness, powerlessness, and existential distress distinguish demoralization from an adjustment reaction, which has been generally ill defined and critiqued as a "wastebasket diagnosis" due to its indiscriminate application (Andreasen \& Wasek, 1980; Tecuta et al., 2015). To date, how adjustment reactions and demoralization might coexist and interact is unexplored in the literature.

Kissane et al. (2001) developed the following six criteria to distinguish demoralization from other conditions: (1) Affective symptoms of existential distress, including hopelessness or loss of meaning 
and purpose in life, are present. (2) Cognitive attitudes of pessimism, helplessness, a sense of being trapped, personal failure or lacking a worthwhile future, and conative absence of drive or motivation to cope differently are experienced. (3) Associated features of social alienation or isolation and lack of support are identified. (4) Emotional intensity fluctuates. (5) Symptoms persist for more than two weeks. (6) A major depressive or other psychiatric disorder is not the primary condition.

\section{Demoralization and Suicide}

Research has shown a strong link between demoralization and suicidality in the context of prolonged psychological distress in people with debilitating conditions, inadequate social supports, adjustment difficulties, and poor quality of life (Boursier, Jover, \& Pringuey, 2013; Kissane et al., 2001; Vehling et al., 2017). As helplessness and hopelessness are the central links between demoralization and suicidality, it is these factors that require a specific focus in interventions (Clarke, Kissane, Trauer, \& Smith, 2005).

It is crucial for social workers to be able to identify demoralization to more effectively assess risk and to intervene. However, as demoralization is not recognized in the DSM (Clarke \& Kissane, 2002), practitioners can be shackled as mental health services do not generally fund treatment for people who do not meet the criteria for a classified diagnosis, and health insurance may not cover demoralization in social work private practice. This creates a problem in meeting criteria for entry into a service. Demoralized people may therefore present repeatedly and remain on social work caseloads as their needs are not being met satisfactorily, creating a cycle of deprivation and, for some, a risk of suicide.

\section{Instruments}

A range of instruments used to measure demoralization have been developed for research and diagnostic purposes. In 2013, de Figueiredo identified five scales that have been used to measure demoralization. The early scales, for example Dohrenwend's Psychiatric Epidemiology Research Interview Demoralization Scale and MMPI-2 Restructured Clinical Scale of Demoralization were developed to measure nonspecific psychological distress rather than demoralization specifically. However, sections of these scales were further developed to measure additional aspects and stages of demoralization. Tecuta et al. (2015) provided a succinct review of the instruments used to measure demoralization.

A recent and most widely used instrument is the Demoralization Scale-II (DS-II). The DS-II is a self-report questionnaire, initially developed by Kissane et al. (2004) and revised by Robinson et al. (2016), consisting of 16 items that span the dimensions of nonspecific dysphoria, disheartenment, loss of confidence and development of subjective incompetence, loss of meaning, hopelessness and helplessness, social disconnectedness, and a desire to die. The DS-II has been used primarily, but not exclusively, with cancer patients. This scale is freely available, can be easily administered and scored, and is suitable for use in social work practice and research with a range of client groups (see Table 1).

\section{THE IMPORTANCE OF DEMORALIZATION IN SOCIAL WORK PRACTICE}

Although the literature on demoralization now spans almost 60 years, contemporary problems of conflict and war, global migrations of people, inequality, food security, climate change, and natural disasters make understanding demoralization of increasing importance to contemporary social work practice and very much relevant to changing world conditions (Frank, 1961; Fronek, 2017).

Understanding demoralization, how it differs from mental illness, and how to respond are important for social work practitioners when working with vulnerable people for two main reasons. The first is to inform how we can best intervene at both interpersonal and structural levels. The second is to be able to fully assess risk factors for individuals given the potential for suicide and the risk of developing mental illness.

Groups of people facing adversity and oppression such as those subjected to racism, homophobia, and other forms of discrimination are more vulnerable to demoralization (Young, 1990). Refugees, immigrants, or migrants who experience language barriers, culture shock, and loss of cultural identity and social status can experience an impaired ability to adapt to foreign environments (Briggs, 2011; Briggs \& Macleod, 2006). Research with refugees and migrants found that unemployment was an important factor in demoralization, and people may be mislabeled as depressed through a nonrecognition of demoralization and cultural misunderstandings (Briggs, 2011, 2013; Kokanovic, Dowrick, Butler, Herrman, \& Gunn, 2008). Lee et al. (2012) suggested that full-time 
Table 1: The Demoralization Scale-II

\begin{tabular}{lccc} 
Item & Never & Sometimes & Often \\
\hline 1 There is little value in what I can offer others & 0 & 1 & 2 \\
2 My life seems pointless & 0 & 1 & 1 \\
3 My role in life has been lost & 0 & 1 & 2 \\
4 I no longer feel emotionally in control & 0 & 1 & 2 \\
5 No one can help & 0 & 1 & 2 \\
6 I feel that I cannot help myself & 0 & 1 & 2 \\
7 I feel hopeless & 0 & 1 & 2 \\
8 I feel irritable & 0 & 1 & 2 \\
9 I do not cope well with life & 0 & 1 & 2 \\
10 I have a lot of regret about my life & 0 & 1 & 2 \\
11 I tend to feel hurt easily & 0 & 1 & 2 \\
12 I feel distressed about what is happening & 0 & 1 & 2 \\
13 I am not a worthwhile person & 0 & 1 & 2 \\
14 I would rather not be alive & 0 & 1 & 2 \\
15 I feel quite isolated or alone & 0 & 0 & 2 \\
16 I feel trapped by what is happening to me & 0 & & 2 \\
\hline
\end{tabular}

For each statement below, please indicate how much (or how strongly) you have felt this way over the last two weeks by circling the corresponding number. Scoring instructions:

Total demoralization score: Sum all 16 items.

Meaning and Purpose subscale: Sum items 1, 2, 3, 5, 6, 7, 13, and 14 .

Distress and Coping Ability subscale: Sum items $4,8,9,10,11,12,15$, and 16

Adapted from S. Robinson, D. W. Kissane, J. Brooker, N. Michael, J. Fischer, M. Franco, et al., "Refinement and Revalidation of the Demoralization Scale: The DS-II-Internal Validity," Cancer, 122, 2251-2259 (2016). Reprinted by permission of John Wiley \& Sons, Inc.

employment protects against demoralization because it offers "a sense of usefulness and belonging." Socioeconomic status, age, education levels, loneliness, and other sociodemographic characteristics have been linked to higher rates of demoralization, suicidal ideation, and suicide attempts (Briggs \& Cooper, 2015; Butterworth et al., 2006). People who depend on income support, especially the unemployed or those people with disabilities, are more likely to report adverse psychological outcomes and suicidal behaviors compared with those who do not depend on the provision of welfare (Butterworth et al., 2006). People affected by natural disasters can experience demoralization particularly when considerable human and material losses occur (Briggs \& Roark, 2013). Kohn (2013) identified demoralization in those people affected by Hurricane Mitch and suggested that measuring demoralization might identify those people at risk of posttraumatic stress disorder.

\section{Interventions}

To date there is little empirical evidence for the effectiveness of specific interventions in working with demoralized people. There is support for psychotherapy, empathic dialogue, logotherapy, narrative therapy, and interpersonal therapy to normalize any sense of unfairness, to foster resilience and hope, and to adjust cognitive distortions, and social connections (de Figueiredo \& Griffith, 2016; Frank, 1974; Griffith, 2018; Kimmel \& Levy, 2013; Strada, 2009; Wein, Sulkes, \& Stemmer, 2010). The best approaches to demoralization are talking therapies and other psychosocial interventions rather than pharmacological prescriptions, except in cases of concomitant mental illness that might require a combination of biomedical intervention and therapy in multidisciplinary practice (O'Keefe \& Ranjith, 2007; Strada, 2009; Wein et al., 2010). Regardless of which theoretical perspective social workers use or where they practice, demoralization is not a redundant issue.

In the medically ill, especially people with terminal illness, existential crises can trigger demoralization. Strada (2009) recommended an existential approach that addresses meaning-of-life concerns, religion, and spirituality. As existentialism has a close relationship with demoralization, existential approaches to therapeutic interventions are likely to be useful in working with demoralized people. According to Payne (2014) existentialism is not only linked to being human, it also focuses on the personal power that people have over their lives and their capacity to change the conditions in which they live. Loss of control is most heightened in those situations that precipitate demoralization, and in such situations people are most vulnerable. 
Demoralization can be triggered by an existential crisis so extreme, hope for the future is eradicated and people struggle to find meaning. Examples of this can be found in the writings of people like Viktor Frankl, who wrote about his survival experience in Nazi concentration camps, and studies on torture victims, prisoners on death row, and today's refugees and asylum seekers in countries where they live for years in refugee camps or are incarcerated indefinitely (Frankl, 1959/2004; Fronek \& Chester, 2016; Schwartz, 2005). An existentialist approach helps people adapt to their changed preexisting assumptions about meaning in their lives rather than seeking to take the pain away.

Positive psychology provides a sound body of knowledge that can help social workers understand how we might intervene with demoralized people (Snyder \& Lopez, 2002). Hopelessness is one of the defining characteristics of demoralization and when hope is lost, risks to the person's physical and mental health are greater. The loss of hope provides a focal point for social work interventions that seek to regenerate hope to reestablish coping. Cognitive-behavioral therapy has been shown to be less effective for severe demoralization, but certain cognitive strategies have the potential to restore hope and a renewed sense of purpose (Connor \& Walton, 2011; Snyder, 1999). Snyder (2000) suggested that people who are hopeful and cope well in adversity have the capacity to find alternative hopeful futures. In other words, they sustain generalized hope or have the ability to generate future visions of a better life while also holding on to smaller, achievable goals. They can hold generalized and specific hopes simultaneously even if they appear contradictory. Thus hope becomes functional. Snyder (1999) suggested cognitive strategies to address self-defeating thoughts. Work in palliative care would suggest that people do develop different pathways through demoralization, for example, hope for a good death and hope for their families rather than hope for a cure (McClement \& Chochinov, 2008).

Griffith (2018) suggested that brief psychotherapy is a useful method of intervention to engender hope and to counter demoralization in people with chronic illness. He documented discreet scenariobased training modules for psychiatry residency training. The modules are designed around single interventions that use evidence-based hope strategies for use across multiple settings. Assessment, formulation, and interventions are addressed using concrete practical strategies grounded in hope theory. Problem solving, goal seeking, emotional regulation, core identity, and relational coping are assessed. Formulation is concerned with mobilizing strengths and hope. Interventions focus on hopebuilding strategies.

Saleebey (2000) identified a strengths approach as important in engendering hope and facilitating change for demoralized people. He emphasized how important it is to learn from people who have not become demoralized in the face of oppression and other traumatic situations, and how others have moved through a state of suffering to a more hopeful future.

A social work perspective would also consider the reality of both external structural factors and interpersonal factors indicating a role for anti-oppressive, radical, and critical approaches that seek to address human rights, oppression, discrimination, and the misuse of power. The case of asylum seekers incarcerated in Australian detention camps who are living without any real hope of release, citizenship, or safety offers a pertinent example (Fronek, 2017). Social workers and other professionals in these settings provided clinical interventions and lobbied for policy change, risking criminal action and incarceration. Addressing structural inequalities or laws that breach human rights complements work conducted at an individual level and can be used concurrently with interpersonal approaches. Macro social work practices that seek change at societal and community levels are supported while providing depth to contextual understandings of person-inenvironment approaches (Kemp, Whittaker, \& Tracy, 1997). It can be argued that for particular groups of people, the prevalence of demoralization may be greatly reduced or indeed eradicated if oppression and injustice are addressed.

An important factor in demoralization is social isolation and exclusion. A sense of meaning, belonging, and social interaction can be supported through involvement in community groups or volunteer organizations, or through employment (Lee et al., 2012; Strada, 2009). The need to address social support and positive family relationships points to important interventions such as the development of personspecific support systems and family therapies to build stronger relationships, find new life meanings, and combat demoralization (Boscaglia \& Clarke, 2007; Walseman, Noblick, \& Norris, 2011). 


\section{CONCLUSION}

Demoralization clearly sits in the psychosocial sphere very much in the realm of social work practice. Demoralization is a useful concept for understanding nonspecific psychological distress in the people whom social workers see every day (Briggs \& Macleod, 2006). As demoralization goes largely unrecognized in social work practice, we wonder about how social workers are intervening. Timely and appropriately targeted psychosocial interventions (individual, family, and community) are important to help vulnerable people who are demoralized or at risk of becoming so. To be truly effective social workers need to be able to identify the factors that affect people's experiences and to know how to best respond to them.

Although important, it is insufficient to limit the focus on demoralization to interventions with demoralized individuals or families. A sociopolitical, macro approach to address structural issues that create the external conditions of oppression and discrimination leading to demoralization is also required. Although tensions have long existed between micro and macro practices (Austin, Coombs, \& Barr, 2005), we suggest that this is a false and unnecessary dichotomy. To work effectively with demoralization, to assess and intervene, social workers must navigate the tensions between approaches that work within systems and those that work toward social reform. Understanding demoralization in micro work requires developing a deep understanding of context, which is rarely achieved by focusing on interpersonal and intrapersonal factors alone. Likewise, the despair and hopelessness of demoralized people should not be forgotten or subsumed by social action. Austin et al. (2005) proposed an ecological approach as a means of bridging this divide and integrating social work practice. Clinician-activist and professional-activist identities have also been proposed (Fronek \& Chester, 2016; Walz \& Groze, 1991).

Existing research and theoretical exploration suggest that there is a place for demoralization in social work practice and research. The demoralization literature provides clearly defined criteria and a measurement tool, the DS-II, that can be easily incorporated into social work practice and research. Given the dramatic social, economic, political, and environmental issues affecting the lives of people throughout the world, there is an urgent need for empirical research on demoralization in social work practice specifically related to its incidence, the utility and effectiveness of specific micro and macro approaches, client experiences, and how social workers navigate the tensions in practice. SW

\section{REFERENCES}

Andreasen, N. C., \& Wasek, P. (1980). Adjustment disorders in adolescents and adults. Archives of General Psychiatry, 37, 1166-1170.

Austin, M. J., Coombs, M., \& Barr, B. (2005). Communitycentered clinical practice: Is the integration of micro and macro social work practice possible? Journal of Community Practice, 13, 9-30.

Bobevski, I., Rowe, H., Clarke, D. M., McKenzie, D. P., \& Fisher, J. (2015). Early postnatal demoralization among primiparous women in the community: Measurement, prevalence and associated factors. $B M C$ Pregnancy and Childbirth, 15, 259. doi:10.1186/ s12884-015-0680-3.

Boscaglia, N., \& Clarke, D. (2007). Sense of coherence as a protective factor for demoralization in women with a recent diagnosis of gynecological cancer. Psychooncology, 16, 189-195.

Boursier, S., Jover, F., \& Pringuey, D. (2013). 2332Relevance of the concept of demoralization in schizophrenic patients. European Psychiatry, 28, 1. doi:10.1016/S0924-9338(13)77176-1

Briggs, L. (2011). Demoralization and psychological distress in refugees: From research to practice. Social Work in Mental Health, 9, 336-345.

Briggs, L. (2013). Is the degree of demoralization found among refugee and migrant populations a socialpolitical problem or a psychological one? European Journal of Psychiatry, 27, 27-35.

Briggs, L., \& Cooper, L. (2015). Demoralization: Exploring the post-migratory experiences of newcomers resettling in Canada. International Journal of Sociology and Social Work, 3, 17-26.

Briggs, L., \& Macleod, A. D. (2006). Demoralisation-A useful conceptualisation of non-specific psychological distress among refugees attending mental health services. International Journal of Social Psychiatry, 52, 512-524.

Briggs, L., \& Macleod, S. (2010). Demoralization or clinical depression? Enhancing understandings of psychological distress in resettled refugees and migrants. World Cultural Psychiatry Research Review, 5, 86-98.

Briggs, L., \& Roark, M. H. (2013). Personal reflections: What happens when disaster hits? Aotearoa New Zealand Social Work, 25, 98-104.

Briggs, L., Talbot, C., \& Melvin, K. (2007). Demoralisation and migration experience. International Review of Modern Sociology, 33, 193-209.

Briskman, L., Zion, D., \& Loff, B. (2011). Care or collusion in asylum seeker detention. Ethics and Social Welfare, 6, 37-55.

Butterworth, P., Fairweather, K., Anstey, K., \& Windsor, T. (2006). Hopelessness, demoralization and suicidal behaviour: The backdrop to welfare reform in Australia. Australian and New Zealand Journal of Psychiatry, 40, $648-656$.

Cheuk, J., Chan, Q., \& Ungvari, G. (2009). Demoralization as a diagnostic conundrum: Case reports. Hong Kong Journal of Psychiatry, 19, 159-163.

Clarke, D., \& Kissane, D. (2002). Demoralization: Its phenomenology and importance. Australian and New Zealand Journal of Psychiatry, 36, 733-742.

Clarke, D. M., Kissane, D. W., Trauer, T., \& Smith, G. C. (2005). Demoralization, anhedonia and grief in 
patients with severe physical illness. World Psychiatry, 4, 96-105.

Connor, M., \& Walton, J. (2011). Demoralization and remoralization: A review of these constructs in the healthcare literature. Nursing Inquiry, 18, 2-11.

de Figueiredo, J. (2013). Distress, demoralization and psychopathology: Diagnostic boundaries. European Journal of Psychiatry, 27, 61-73.

de Figueiredo, J., \& Frank, J. (1982). Subjective incompetence, the clinical hallmark of demoralization. Comprehensive Psychiatry, 23, 353-363.

de Figueiredo, J. M., \& Griffith, J. L. (2016). Chronic pain, chronic demoralization, and the role of psychotherapy. Journal of Contemporary Psychotherapy, 46, 167-177.

Fang, C.-K., Chang, M.-C., Chen, P.-J., Lin, C.-C., Chen, G.-S., Lin, J., et al. (2014). A correlational study of suicidal ideation with psychological distress, depression, and demoralization in patients with cancer. Supportive Care in Cancer, 22, 3165-3174.

Florijn, B. W. (2018). Extending euthanasia to those 'tired of living' in the Netherlands could jeopardize a wellfunctioning practice of physicians' assessment of a patient's request for death. Health Policy, 122, 315-319. doi:10.1016/j.healthpol.2018.01.007

Frank, J. D. (1961). Persuasion and healing: A comprehensive study of psychotherapy. Baltimore: Johns Hopkins University Press.

Frank, J. D. (1974). Psychotherapy: The restoration of morale. American Journal of Psychiatry, 131, 271-274.

Frankl, V. (1959/2004). A man's search for meaning. London: Rider, Ebury.

Fronek, P. (2017). Social work in a brave new world. In A. L. Pelaez \& E. R. Diez (Eds.), Social work research and practice: Contributions to a science of social work (pp. 33-50). Spain: Thomas Reuters Aranzadi.

Fronek, P., \& Chester, P. (2016). Moral outrage: Social workers in the Third Space. Ethics and Social Welfare, 10, 163-176.

Gabel, S. (2011). Addressing demoralization in clinical staff: A true test of leadership. Journal of Nervous and Mental Disease, 199, 892-895.

Gabel, S. (2012a). Demoralization: A precursor to physician burnout? American Family Physician, 86, 861-862.

Gabel, S. (2012b). Demoralization in mental health organizations: Leadership and social support help. Psychiatric Quarterly, 83, 489-496.

Gabel, S. (2013). Demoralization in health professional practice: Development, amelioration, and implications for continuing education. Journal of Continuing Education in the Health Professions, 33, 118-126.

Grassi, L., Costantini, A., Kissane, D., Brunetti, S., Caruso, R., Piazza, G., et al. (2017). The factor structure and use of the Demoralization Scale (DS-IT) in Italian cancer patients. Psycho-Oncology, 26, 1965-1971.

Griffith, J. L. (2018). Hope modules: Brief psychotherapeutic interventions to counter demoralization from daily stressors of chronic illness. Academic Psychiatry, 42, 135-145

Griffith, J., \& Gaby, L. (2005). Brief psychotherapy at the bedside: Countering demoralization from medical illness. Psychosomatics, 46, 109-116.

Hocking, D., \& Sundram, S. (2015). Demoralization syndrome does not explain the psychological profile of community-based asylum-seekers. Comprehensive Psychiatry, 63, 55-64.

Kemp, S., Whittaker, J. K., \& Tracy, E. M. (1997). Personenvironment practice: The social ecology of interpersonal helping. New York: Aldine de Gruyter.

Kimmel, R., \& Levy, M. (2013). Brief psychotherapy for demoralization in terminal cancer: A case report. Psychosomatics, 54, 84-87.
Kissane, D. (2004). The contribution of demoralization to end of life decision making. Hastings Center Report, 34, 21-31.

Kissane, D. W. (2014). Demoralization: A life-preserving diagnosis to make for the severely medically ill. Journal of Palliative Care, 30, 255-258.

Kissane, D. W., Clarke, D. M., \& Street, A. F. (2001). Demoralization syndrome: A relevant psychiatric diagnosis for palliative care. Journal of Palliative Care, 17, $12-21$

Kissane, D., Wein, S., Love, A., Lee, X., Kee, P., \& Clarke, D. (2004). The Demoralization Scale: A report of its development and preliminary validation. Journal of Palliative Care, 20, 269-276.

Kohn, R. (2013). Demoralization and the longitudinal course of PTSD following Hurricane Mitch. European Journal of Psychiatry, 27, 18-26.

Kokanovic, R., Dowrick, C., Butler, E., Herrman, H., \& Gunn, J. (2008). Lay accounts of depression amongst Anglo-Australian residents and East African refugees. Social Science and Medicine, 66, 454-466.

Lee, C. Y., Fang, C. K., Yang, Y. C., Liu, C. L., Leu, Y. S., Wang, T. E., et al. (2012). Demoralization syndrome among cancer outpatients in Taiwan. Supportive Care in Cancer, 20, 2259-2267.

McClement, S. E., \& Chochinov, H. M. (2008). Hope in advanced cancer. European Journal of Cancer, 44, 1169-1174.

McKenzie, D. P., Clarke, D. M., Forbes, A. B., \& Sim, M. R. (2010). Pessimism, worthlessness, anhedonia, and thoughts of death identify DSM-IV major depression in hospitalized, medically ill patients. Psychosomatics, 51, 302-311.

Nanni, M. G., Caruso, R., Sabato, S., \& Grassi, L. (2018). Embitterment in psychological trauma: Demoralization and embitterment. Psychological Trauma, 10, 14-21.

O'Keefe, N., \& Ranjith, G. (2007). Depression, demoralization or adjustment disorder? Understanding emotional distress in the severely ill. Clinical Medicine, 7, 478-481.

Payne, M. (2014). Modern social work theory (4th ed.). Houndsmill, Basingstoke, Hampshire: Palgrave Macmillan.

Robinson, S., Kissane, D. W., Brooker, J., Michael, N., Fischer, J., Franco, M., et al. (2016). Refinement and revalidation of the Demoralization Scale: The DS-IIinternal validity. Cancer, 122, 2251-2259.

Saleebey, D. (2000). Power in the people: Strengths and hope. Advances in Social Work, 1, 127-136.

Sansone, R., \& Sansone, L. (2010). Demoralization in patients with medical illness. Psychiatry, 7, 42-45.

Schwartz, H. I. (2005). Death row syndrome and demoralization. Journal of the American Academy of Psychiatry and the Law Online, 33, 153-155.

Slavney, P. R. (1999). Diagnosing demoralization in consultation psychiatry. Psychosomatics, 40, 325-329.

Snyder, C. R. (1999). Hope, goal-blocking thoughts, and test-related anxieties. Psychological Reports, 84, 206-208.

Snyder, C. R. (Ed.). (2000). Handbook of hope: Theory, measures and applications. San Diego: Academic Press.

Snyder, C. R., \& Lopez, S. J. (Eds.). (2002). Handbook of positive psychology. Oxford, England: Oxford University Press.

Strada, E. (2009). Grief, demoralization, and depression: Diagnostic challenges and treatment modalities. Primary Psychiatry, 16, 49-55.

Tecuta, L., Tomba, E., Grandi, S., \& Fava, G. A. (2015). Demoralization: A systematic review on its clinical characterization. Psychological Medicine, 45, 673-691.

Townsend, K. (2018). Demoralisation in palliative care. Lancet Oncology, 19, 168. 
Vehling, S., Kissane, D. W., Lo, C., Glaesmer, H., Hartung, T. J., Rodin, G., \& Mehnert, A. (2017). The association of demoralization with mental disorders and suicidal ideation in patients with cancer. Cancer, 123, 3394-3401.

Walseman, K., Noblick, J., \& Norris, L. (2011). Finding meaning at the end of life. Psychiatric Annals, 41, $450-452$.

Walz, T., \& Groze, V. (1991). The mission of social work revisited: An agenda for the 1990s. Social Work, 36, 500-504.

Wein, S., Sulkes, A., \& Stemmer, S. (2010). The oncologist's role in managing depression, anxiety, and demoralization with advanced cancer. Cancer Journal, 16, 493-499.

Young, I. M. (1990). Abjection and oppression: Dynamics of unconscious racism, sexism and homophobia. In A. B. Dallery \& C. E. Scott (Eds.), Crises in continental philosophy (pp. 62-63). Albany: State University of New York Press.

Lynne Briggs, PhD, PGD Social Work, MSW (Research), is associate professor and Patricia Fronek, PhD, BSW, is BSW program director, School of Human Services and Social Work, Griffith University, Gold Coast, Queensland, Australia. Address correspondence to Lynne Briggs, School of Human Services and Social Work, Griffith University, G01:300A, Parklands Drive, Southport, Gold Coast, Queensland 4222, Australia; e-mail: l.briggs@, griffith.edu.au.

Original manuscript received March 11, 2018

Final revision received May 9, 2018

Editorial decision June 7, 2018

Accepted June 15, 2018 